\title{
McCune-Albright Syndrome
}

National Cancer Institute

\section{Source}

National Cancer Institute. McCune-Albright Syndrome. NCI Thesaurus. Code C48627.

A syndrome characterized by the presence of polyostotic fibrous dysplasia, cafe-au-lait skin lesions, and sexual precocity. It is caused by mutations within the GNAS genetic locus. 